\title{
The Prospects of Applying of Technologies of Nonlinear Stimulation Therapy to Treat Amblyopia
}

\author{
Zueva Marina V $^{1 *}$ and Maghlakelidze Natalia ${ }^{2}$ \\ ${ }^{1}$ Department of Clinical Physiology of Vision of Moscow Helmholtz Research Institute of Eye Diseases, Ministry of Healthcare of Russian Federation, \\ Russia
}

${ }^{2}$ Department of Ophthalmology, Aversi Clinic Ltd, Georgia

Submission: March 13, 2017; Published: April 18, 2017

*Corresponding author: Zueva Marina V, Head of the Department of Clinical Physiology of Vision, Moscow Helmholtz Research Institute of Eye Diseases, Moscow, Russia, Tel: +7 916576 2359; Email: visionlab@yandex.ru

\begin{abstract}
The theory of "fractality of sensations" links to the development and maintenance of the optimal complexity of the networks and functional activity of the brain with the complexity of the visual and other environmental signals that affect the person during the life. The need to control and maintain healthy fractal dynamics during the lifespan by using the natural and artificial cues of complex structure and dynamics was substantiated. In pathological conditions, when the dynamics of the rhythmic brain activity is disordered, or a simplification of visible environmental stimuli occurs, technologies of nonlinear stimulation therapy can be especially helpful. The use of complex stimuli can promote recovery of the brain in the aging, neurodegenerative diseases and amblyopia, acting through the reactivation of neuroplasticity. We argue here that nonlinear stimulation therapy can significantly enhance the effectiveness of the treatment of amblyopia. We believe that the increasing the plasticity potential, bringing it closer to that characterizes critical periods in the CNS development will significantly enhance the effectiveness of amblyopia treatment not only in children but also in the adult. Possible technical solutions for improving training video-games in the treatment of amblyopia are discussed based on the using the flashing background of various complexity.
\end{abstract}

Keywords: Nonlinear stimulation therapy; Brain plasticity; Autism spectrum disorders; Amblyopia

Abbreviations: CNS: Central Nervous System; EE: Environmental Enrichment

\section{Introduction}

We evolve the theory that links to the development and maintenance of the normal complexity of the neural networks and the functional activity of the brain with the complexity of the visual and other environmental signals that affect the human during his or her life [1]. The experience of nonlinear stimulation by environmental incentives of complex patterns and dynamics should be considered as the crucially essential condition for normal maturation and aging of the brain. Hence, we state the need to control and maintain healthy fractal dynamics during the life by using the natural and artificial cues of complex structure and dynamics. The theory of 'fractality of sensation' justifies the need to maintain a complex nonlinear dynamics in diseases of the retina and the brain, and in different situations that lead to simplification of the pattern of neural activity and brain structure.
In pathological conditions, when the dynamics of the brain activity is disordered [2,3] or when a simplification of natural visible environmental stimuli occurs on different causes, the artificial fractal cues in technologies of nonlinear stimulation therapy seem to be particularly useful. We noted earlier that the use of complex stimuli could promote recovery of the brain in neurodegenerative diseases and amblyopia, acting through the reactivation of neuro plasticity $[1,4]$.

Further developing these ideas, here we would like to emphasize that nonlinear stimulation therapy can significantly enhance the effectiveness of the treatment of amblyopia. This effect can be expected, since the aperiodic stimuli of the deterministic-chaotic dynamics, in our opinion, should reactivate the plasticity of the brain more efficiently in comparison with periodic stimuli of a deterministic dynamics. We believe that 
the increasing the plasticity potential, bringing it closer to that high level that characterizes the critical periods in the early CNS development will significantly enhance the effectiveness of amblyopia treatment not only in children but also in adult patients with amblyopia that is not amenable to conventional treatment.

\section{Amblyopia and Brain Plasticity}

Plasticity is the ability of a nervous tissue to an adaptive restructuring as a result of experience, the effects of endogenous and exogenous factors at different stages of the development, in the course of recovery and reorganization after the harmful effects of the environment [5]. The plasticity of the brain is known to play a crucial role in the development of CNS and highly contributes to mechanisms of learning and memory. Impacts of the environment factors on the brain in the early development induce changes in neural connections that provide the refinement of the brain structure by using mechanisms of synaptic and homeostatic plasticity. Synapse-specific Hebbian plasticity including the long-term potentiation and long-term depression contribute to regulation of overall levels of neuronal and network activity. Synapses alter their strength under the influence of its activity and other impacts. Such mechanisms can regulate levels of activity as synaptic scaling, spike-timing dependent plasticity, and synaptic redistribution [6]. Windows of enhanced plasticity during the development called the critical and sensitive periods. These are the periods when the entering information of environment is essential for the proper development of specific neural circuits in the brain. If the neural network is not stimulated, a shortage of brain function served by this network will continue [7-9]. Amblyopia is a developmental disorder, which is associated with the insufficient multi-sensory experience during critical periods early in the development $[10,11]$. During critical periods, alterations in the structure and function of the experience-dependent neuronal circuits undergo the influences of endogenous or exogenous factors [12]. The dynamics of the processes of the excitation and inhibition provides the control of the timing of critical periods. In the early postnatal life, the majority of neuronal contacts are excitatory. The maturation process of the brain increases inhibitory neurotransmission, and when it reaches a certain threshold, the critical period switches off [13].

The human brain is always changing and the potential of plasticity reduced [14-16]. After the closing the critical periods, many factors, which guide the development of the brain, such as growth factors, are down-regulated, but in the adult brain, they can be up-regulated again re-activating the neuroplasticity, for example, as a response to injury of the brain [14]. A potential of the plasticity can be reinforced with the help of various learning technologies, including physical and perceptive training. Many methods of reactivation of neuroplasticity are considered within the framework of the concept of the "Environmental Enrichment" (EE) $[13,17-22]$.
The EE includes the laboratory conditions to ensure higher levels of multisensory stimulation, physical activity and social interaction, which causes the exploratory behavior [9]. In rodents, the EE conditions were demonstrated to change the morphology and thickness of cortical neurons, especially in the hippocampus and visual cortex, the changes in gene expression and secretion of neurotrophic factors [19].

Prenatal environmental enrichment was shown to modulate fetal development. In experimental studies in rats, the increase in the level of physical activity during gestation increased levels of IGF-1 in the mother's bloodstream; and then its production in the layer of fetal retinal ganglion cells was observed [13]. IGF, in turn, stimulated the maturation of neural circuit, the retinal neural network.

The recovery of visual acuity was found when placing adult amblyopic rats in an enriched environment for three weeks with a motor or visual enrichment [9]. The full recovery of visual acuity of the amblyopic eye was shown in rats with a running wheel, toys, and perceptive training in the cage. This visual effect was accompanied by a reduction of the balance of the excitation/ inhibition in the visual cortex.

Some studies show a significant degree of plasticity in the visual system of adults with amblyopia following training suggesting that perceptual learning reflects alterations in early level neural processing [23-27]. Video games were found to improve substantially spatial vision functions (visual acuity, spatial attention, and stereo acuity) on low-and high-levels of visual processing $[28,29]$.

\section{The application of stimuli of complex dynamics in the therapy of amblyopia}

The evolution of man on Earth and his adaptation to the natural conditions is occurring in a nonlinear world, in an environment characterized by a variety of fractal objects and processes. The natural noises with different dynamics affect the adaptation of living systems to environmental conditions and may determine the population alteration [30-32]. It was documented in numeral studies that the fractal regulation of the rhythmic activity is impaired with age and in diseases, and the highly ordered or highly random dynamics of fluctuations are developed [1].

The noted above beneficial effect of perceptual learning in amblyopia was assumed to operate via a reduction in the internal neural noise and through more efficient use of the stimulus information $[26,33]$.

It is known that spontaneous neuronal activity (one of the sources of the internal retinal noise) plays a significant role in the retina, in the early postnatal life promoting the synapse formation [34]. Spontaneous network spike activity in the retinal ganglion cells plays a significant role in the initial establishment of synaptic connections during development [35], and sets a 
basis for refinement of neural circuits and brain connectivity. The formation of a mature scheme of synaptic contacts in the retina occurs in two stages [34]. The first step in prenatal and early postnatal periods includes forming a plurality of disordered synaptic contacts. The second stage is triggered by the beginning of the sensory experience and leads to the reorganization of the synaptic connections promoting the fine circuit of useful neuronal contacts. The retinal noise is believed to contribute an encoding of impulses of retinal ganglion cells, and the temporal contrast sensitivity and temporal tuning of the visual cortex [36].

We believe that the effects of visual stimuli of complex dynamics and the combination of stochastic and deterministic chaotic noises in stimulation therapy are promising as methods for tuning the temporal sensitivity of the visual system and reactivating the plasticity of neurons throughout the visual pathway. These mechanisms, in our opinion, should facilitate the reconfiguration and refinement of the neuronal connection scheme, ensuring restoration of visual acuity of patients with amblyopia of different ages.

In the amblyopia, the loss of complexity of images created by the brain may occur following the reduction in the intensity of light reaching the retina, which reduces or distorts the perception of the geometric and dynamic fractals of nature. A decrease of the contrast of the observing objects alters the perception of the small details and geometric complexity of the object. Therefore, the decrease in the transparency of optical media and violations of eye refraction, apparently, reduce the complexity of the image formed on the retina or images processed by the brain.

In patients with strabismic or anisometropic amblyopia, the reduced monocular vision is combined with reduced or absent binocular function [37]. Because amblyopia often involves one eye, this pathological condition is considered as a monocular pathology [38]. Respectively, the most common treatment methods are directed at recovering of a monocular function [39-41]. They based on the patching the good eye to force the amblyopic eye improving acuity. Lately, due to the presence of residual amblyopia and frequent recurrence after the patching treatment is stopped [42] the monocular methods for the treatment of amblyopia have been questioned.

The hypothesis $[43,44]$ considered the amblyopia as an intrinsically binocular pathology, and a reduction of visual acuityas a consequence of the violation of binocular vision. Binocular disorders were supposed to be the basis of the pathogenesis of all types of amblyopia [38,43]. Therefore, the new binocular methods of the treatment amblyopia were proposed to restore binocular vision, thereby restoring and monocular acuity. These authors revealed that when the strength of the signal to the fellow eye was reduced, the amblyopes began combining the information between two eyes [44]. Artificial conditions under which binocular vision take place, lead to an improving binocular vision. Authors substantiated that this finding is the basis for a new binocularly-based treatment of amblyopia. In this therapeutics, the measurement and treatment of suppression were set as a first step, which in many cases can lead to a reestablishment of stereoscopic function and a reduction in the deficit of monocular visual acuity.

We support that the treatment of amblyopia should begin with the restoration of binocular interaction. However, in our opinion, it is crucial that the treatment also includes the séances of nonlinear visual stimulation. The visual stimulation with complex stimuli can represent a separate additional therapeutics or to be an essential element of binocular treatment. Considering the above-mentioned binocular training methods of the treatment with a video game "Tetris" [43], perhaps, the presenting falling blocks on the background of non-periodic flickering with fractal dynamics would be more useful. We suppose that the recovery of binocular and stereoscopic vision under dichoptic conditions by the different training video games or the other training programs will be more efficient if a fractal background is present, which includes a visual stimulation with low-intensity flashes of light with complex, deterministic-chaotic dynamics.

\section{Conclusion}

The nonlinear stimulation therapy with visual stimuli of given complex dynamics can be the promising way promoting the significant enhancement of the efficiency of the treatment of amblyopia in children and adult acting through the reactivation of neuroplasticity. In the existent training video-games for amblyopes, it is relevant to use the flashing background of various complexities. It is also advisable to use technologies of fractal photo-stimulation of a different design, not combined with video games.

\section{References}

1. Zueva MV (2015) Fractality of sensations and the brain health: the theory linking neurodegenerative disorder with distortion of spatial and temporal scale-invariance and fractal complexity of the visible world. Front Aging Neurosci 7: 135.

2. Hausdorff JM, Peng CK, Ladin Z, Wei JY, Goldberger AL (1995) Is walking a random walk? Evidence for long-range correlations in stride interval of human gait. J Appl Physiol 78(1): 349-358.

3. Goldberger AL (1997) Fractal variability versus pathologic periodicity: complexity loss and stereotypy in disease. Perspect Biol Med 40(4): 543-561.

4. Zueva MV (2013) Dynamic Fractal Flickering as a Tool in Research of Non-Linear Dynamics of the Evoked Activity of a Visual System and the Possible Basis for New Diagnostics and Treatment of Neurodegenerative Diseases of the Retina and Brain. World Applied Sciences Journal 27(4): 462-468.

5. Bengoetxea H, Ortuzar N, Bulnes S, Rico-Barrio I, Vicente Lafuente J, et al. (2012) Enriched and deprived sensory experience induces structural changes and rewires connectivity during the postnatal development of the brain. Neural Plasticity 2012: 1-10.

6. Abbott LF, Nelson SB (2000) Synaptic plasticity: taming the beast. Nat Neurosci 3(Suppl): 1178-1183.

7. Hensch T (2005) Critical period plasticity in local cortical circuit. Nat Rev Neurosci 6(11): 877-888. 
8. Hensch TK, Fagiolini M (2005) Excitatory-inhibitory balance and critical period plasticity in developing visual cortex. Prog Brain Res 147: 115-124.

9. Baroncelli L, Braschi C, Spolidoro M, Begenisic T, Sale A, et al. (2010) Nurturing brain plasticity: impact of environmental enrichment. Cell Death Differ 17(7): 1092-1103.

10. Holmes JM, Clarke MP (2006) Amblyopia. Lancet 367(9519): 1343 1351.

11. Barnes GR, Li X, Thompson B, Singh KD, Dumoulin SO, et al. (2010) Decreased gray matter concentration in the lateral geniculate nuclei in human amblyopes. Invest Ophthalmol Vis Sci 51: 1432-1438.

12. Black JE (1998) How a child builds its brain: some lessons from animal studies and neural plasticity. Preventative Medicine 27(2): 168-171.

13. Sale A, Berardi N, Maffei L (2012) Environmental influences on visual cortex development and plasticity. In: Molotchikoff S, Rauat J (Eds.), Visual Cortex-Current Status and Perspectives, In Tech, Croatia.

14. Eysel UT (2009) Adult Cortical Plasticity. Bochum, Ruhr-University Bochum, Germany.

15. Gilbert CD, Li W (2012) Adult visual cortical plasticity. Neuron 75(2): 250-264.

16. Sur M, Naqakura I, Chen N, Sugihara H (2013) Mechanisms of plasticity in the developing and adult visual cortex. Proq Brain Res 207: 243-254.

17. Sale A, Maya-Vetencourt JF, Medini P, Cenni MC, Baroncelli L, et al. (2007) Environmental enrichment in adulthood promotes amblyopia recovery through a reduction of intracortical inhibition. Nat Neurosci 10(6): 679-681

18. Mora F, Segovia G, del Arco A (2007) Aging, plasticity and environmental enrichment: structural changes and neurotransmitter dynamics in several areas of the brain. Brain Res Rev 55(1): 78-88.

19. Maya-Vetencourt JF, Origlia N (2012) Visual cortex plasticity: a complex interplay of genetic and environmental influences. Neural Plast 2012 1-14.

20. Baroncelli L, Bonaccorsi J, Milanese M, Bonifacino T, Giribaldi F, et al. (2013) Enriched experience and recovery from amblyopia in adult rats: impact of motor, social and sensory components. Neuropharmacology 62(7): 2388-2397.

21. Alwis DS, Rajan R (2014) Environmental enrichment and the sensory brain: the role of enrichment in remediating brain injury. Front Syst Neurosci 8: 156.

22. van Praag H, Kempermann G, Gage FH (2000) Neural consequences of environmental enrichment. Nat Rev Neurosci 1(3): 191-198.

23. Levi DM, Polat U (1996) Neural plasticity in adults with amblyopia. Proc Natl Acad Sci USA 93(13): 6830-6834.

24. Polat U, Ma-Naim T, Belkin M, Sagi D (2004) Improving vision in adult amblyopia by perceptual learning. Proc Natl Acad Sci 101(17): 66926697.

25. Levi DM (2005) Perceptual learning in adults with amblyopia: a reevaluation of critical periods in human vision. Dev Psychobiol 46(3): 222-232.
26. Levi DM, Li RW (2009) Perceptual learning as a potential treatment for amblyopia: a mini-review. Vision Res 49(21): 2535-2549.

27. To L, Thompson B, Blum JR, Maehara G, Hess RF, et al. (2011) A game platform for treatment of amblyopia. IEEE Trans Neural Syst Rehabil Eng 19(3): 280-289.

28. Green CS, Bavelier D (2007) Action-video-game experience alters the spatial resolution of vision. Psychol Sci 18(1): 88-94.

29. Li J, Thompson B, Deng D, Chan LY, Yu M, et al. (2013) Dichoptic training enables the adult amblyopic brain to learn. Curr Biol 23(8): 308-309.

30. Halley JM (1996) Ecology, evolution and 1/f -noise. Trends Ecol Evol 11(1): 33-37.

31. Halley JM, Inchausti P (2004) The increasing importance of $1 / \mathrm{f}$ noise as models of ecological variability. Fluctuation and Noise Letters 4(2): R1-R26.

32. Vasseur DA, Yodzis P (2004) The color of environmental noise. Ecology 85(4): 1146-1152.

33. Freiherr J, Lundstrom JN, Habel U, Reetz K (2013) Multisensory integration mechanisms during aging. Front Hum Neurosci 7: 863.

34. Tian N (2008) Synaptic activity, visual experience and the maturation of retinal synaptic circuitry. J Physiol 586(18): 4347-4355.

35. Feller M, Blankenship A (2008) The function of the retina prior to vision: The phenomenon of retinal waves and retinotopic refinement. In: LM Chalupa, RW Williams (Eds.), Eye, retina, and visual system of the mouse. MIT Press, Cambridge, USA, pp. 343-351.

36. Passaglia CL, Troy JB (2004) Impact of Noise on Retinal Coding of Visual Signals. J Neurophysiol 92(2): 1023-1033.

37. Hess RF, Thompson B (2015) Amblyopia and the binocular approach to its therapy. Vision Res 114: 4-16.

38. Birch EE (2013) Amblyopia and binocular vision. Prog Retin Eye Res 33: 67-84.

39. Wick B, Wingard M, Cotter S, Scheiman M (1992) Anisometropic amblyopia: is the patient ever too old to treat? Optom Vis Sci 69(11): 866-878.

40. de Zárate BR, Tejedor J (2007) Current concepts in the management of amblyopia. Clin Ophthalmol 1(4): 403-414.

41. Bretas CC, Soriano RN (2016) Amblyopia: neural basis and therapeutic approaches. Arq Bras Oftalmol 79(5): 346-351.

42. Bhola R, Keech RV, Kutschke P, Pfeifer W, Scott WE (2006) Recurrence of amblyopia after occlusion therapy. Ophthalmology 113(11): 20972100.

43. Mansouri B, Thompson B, Hess RF (2008) Measurement of suprathreshold binocular interactions in amblyopia. Vision Res 48(28): 2775-2784.

44. Hess RF, Mansouri B, Thompson B (2010) A binocular approach to treating amblyopia: antisuppression therapy. Optom Vis Sci 87(9): 697-704. 
This work is licensed under Creative

Commons Attribution 4.0 Licens

DOI: $10.19080 / G J I D D .2017 .01 .555556$
Your next submission with Juniper Publishers will reach you the below assets

- Quality Editorial service

- Swift Peer Review

- Reprints availability

- E-prints Service

- Manuscript Podcast for convenient understanding

- Global attainment for your research

- Manuscript accessibility in different formats

(Pdf, E-pub, Full Text, Audio)

- Unceasing customer service

Track the below URL for one-step submission https://juniperpublishers.com/online-submission.php 